\title{
Establishing The Challenges Affecting South African SMEs
}

Michael C. Cant, University of South Africa, South Africa

Johannes A. Wiid, University of South Africa, South Africa

\begin{abstract}
Cant and Ligthelm (2003) estimate that 70-80 percent of SMEs fail. A number of elements and challenges have been identified as contributing factors to the high failure rate of SMEs in South Africa. The research investigates the extent to which the identified variables affect South African SMEs. The objective of this paper is to determine to what extent SMEs experience selected challenges or issues that negatively influence the success of the business. Challenges and issues include exogenous macro environmental variables and endogenous environmental variables, namely marketing. A questionnaire was constructed and judgement sampling was used to gather the responses of 81 SMEs. The research identified inflation and interest rates, crime and unemployment, low demand for products, the wrong pricing strategies implemented and the location of the business to be the major problems experienced by SMEs. The challenge now is to improve the skills and capabilities of SMEs to ensure their success as they play a vital role in the South African economy.
\end{abstract}

Keywords: Business Problems; South Africa; SMEs; Marco Environment; Micro Environment; Marketing

\section{INTRODUCTION}

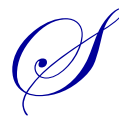

MEs play a crucial role in almost all economies but particularly in developing countries with major employment and income distribution challenges, such as South Africa. The creation and sustainability of new SMEs are vital to the economic prosperity of a country or else it risks an economic stagnation (Fatoki \& Garwe, 2010). Kongolo (2010) states that SMEs account for roughly 91 percent of the formal business entities, contributing between 51- and 57 percent to the GDP and 60 percent of employment in South Africa. However, many small businesses within South Africa do not make it past the second year of trading with failure rates as high as 63 percent (Roberts, 2010). SMEs like any other business entity are exposed to various macro environmental variables however some of the main issues faced by SMEs include marketing, management, social, human resources and financial related matters.

The aim of this research was to establish the challenges affecting South African SMEs. Previous research conducted by Fatoki and Garwe (2010) investigated internal (access to finance, management skills, networking, investment information technology and cost of production) and external environmental (economic environment, markets, infrastructure, crime, corruption, labour and regulations) factors that can and will have an impact on a business and focused on obstacles to the growth of new SMEs in South Africa. On the other hand, Fatoki and Odeyemi (2010) focused on financial related challenges whereas van Scheers (2012) and Cant (2012) focused on marketing related challenges and marketing skills shortages experienced by South African SMEs and their implications for success. This study provides a holistic view of the various problems experienced in running a South African SME namely; lack of marketing knowledge and management skills, social influences and lastly, human resources and financial related matters. Brink, Cant and Ligthelm (2003) conducted a similar study which indicated the role and effect of various macro environmental changes on the success of businesses.

Many SMEs fail in spite of support from government and private initiatives that support and develop small businesses. SMEs experience problems not only during economic downturns but also during economic progress (Kongolo, 2010). The aim of this study was to identify the major elements and problems affecting South African 
SMEs. The research methodology is explained, followed by the literature review, which confirms the research findings discussed after which some recommendations are made.

\section{RESEARCH OBJECTIVES}

The main aim of the study was to establish which challenges are perceived to negatively influence South African SMEs by examining the following research questions:

- Which macro environmental variables have an impact on South African SMEs?

- $\quad$ Does the lack of marketing knowledge negatively affect the success of South African SMEs?

\section{RESEARCH METHODOLOGY}

The research followed a quantitative analysis of the research question to establish what the major macro environmental and marketing related problems affecting South African SMEs are. To address this problem adequately, the research methodology was based on the primary data collected from South African SMEs. The sample consisted of 81 SMEs operating in the Tshwane area. To achieve a low level of error, judgement sampling method was used. The questionnaire consisted of a set of questions which were divided into two major sections. The first section relates to the demographics, which describe the profile of the respondent in terms of position, involvement, and level of education, gender, age and race. The second part of the questionnaire investigated the perceptions of the problems experienced by SMEs. The main constructs of this study are marketing, and management problems which were measured through Likert-type scales. The basic Likert scale consisted of five points with labels ranging from strongly disagree to strongly agree. The data is quantified and analysed by examining the frequency of occurrences and the importance of the problem. A frequency distribution will be used once all the data has been accumulated. Zikmund (2009) states that a frequency distribution shows in absolute or relative terms how often the different values of the variable are actually encountered in the sample.

\section{LITERATURE REVIEW}

A SME is described by the National Small Business Act of South Africa of 1996, as amended in 2003, as: “... a separate distinct entity including cooperative enterprises and non-governmental organisations managed by one owner or more, including branches or subsidiaries if any is predominately carried out in any sector or subsector of the economy mentioned in the schedule of size standards and can be classified as SME by satisfying the criteria mentioned in the schedule of size standards" (Government Gazette of the Republic of South Africa, 2008). The various challenges identified that prevent the creation of new SMEs are also those that are the cause of the high failure rates within South Africa and are discussed below.

\section{Macro and Market Environment}

SMEs like any other business entity need to be aware of changes in the external environment, which includes changes taking place in the economic, social, political, technological and international environment. The major variables that impact South African SMEs include interest and exchange rates, inflation, unemployment, crime, HIV/Aids, technological advancements and government legislation (Brink \& Cant, 2003). It is crucial that the owner or manager be aware of these external variables to minimise any negative effects and be able to swiftly adapt to these changes in order to take advantage of possible opportunities as well as to ward off any threats (Sha, 2006).

As with all businesses, SMEs face challenges posed by the economic climate in a country as the economic factors have a direct impact on the consumption patterns of consumers and significantly affects all businesses in all sectors (Fatoki \& Garwe, 2010). A few years ago the interest rate was more than 18 percent which had a significant impact on consumers and businesses alike in terms of spending power. Since the economic slowdown from 2008, interest rates worldwide has dropped with some countries having a 1 percent interest rate and South Africa standing at a prime rate of 7 percent - the lowest in decades. Economic variables include interest and exchange rates and inflation, all of which influences the demand for goods and services (Fatoki \& Garwe, 2010). Another serious 
macro environmental factor is the high levels of crime in South Africa. Due to the high incidents of crime, businesses are incurring huge costs to safeguard not only goods but customers as well. In addition, SMEs in South Africa, as is the case all over the world, have to pay registration and licenses fees and pay taxes as part of government legislation which has an impact on its growth (Fatoki \& Garwe, 2010). A good knowledge of the market environment is also required for SMEs. They need to know who their customers are, what they buy, how they buy, where they buy and when they buy in order to be able to meet their needs and demands - and to survive. The target market area is therefore very important to a business as the composition of this environment has an impact on the skills needed and the actions to be followed. This environment also includes the competitors in the market and it is imperative that the business knows who they are, where they are and what they offer.

\section{Micro Environment}

Insufficient management skills, expertise in functional areas such as marketing and human resources, and financial knowledge are the major causes of SME failures (Brink \& Cant, 2003). The most relevant issue faced by most SMEs are marketing related problems.

Marketing is a fundamental yet overwhelming concept for most SMEs as many struggle to employ it effectively (Van Scheers, 2012). Marketing factors such as competition, low demand for products, not being able to meet customer needs, wrong pricing strategies, lack of knowledge, poor location, product variety and branding, all have an impact on SMEs. Dockel and Ligthelm (2009) point out that SMEs undertake little marketing activities as they have difficulties managing the various marketing challenges stated above. Secondary research indicate that SME owners' perception on marketing related challenges is that they lack time or funds to invest in research to establish their target market, customer trends and marketing in general (Van Scheers, 2012).

\section{RESEARCH FINDINGS}

The previous section provided a review of literature on problems experienced by SMEs. This section reports on the key findings from the research conducted. Completed questionnaires were received from 81 respondents $(\mathrm{n}=81)$ who either own or manage a SME in the Tshwane area.

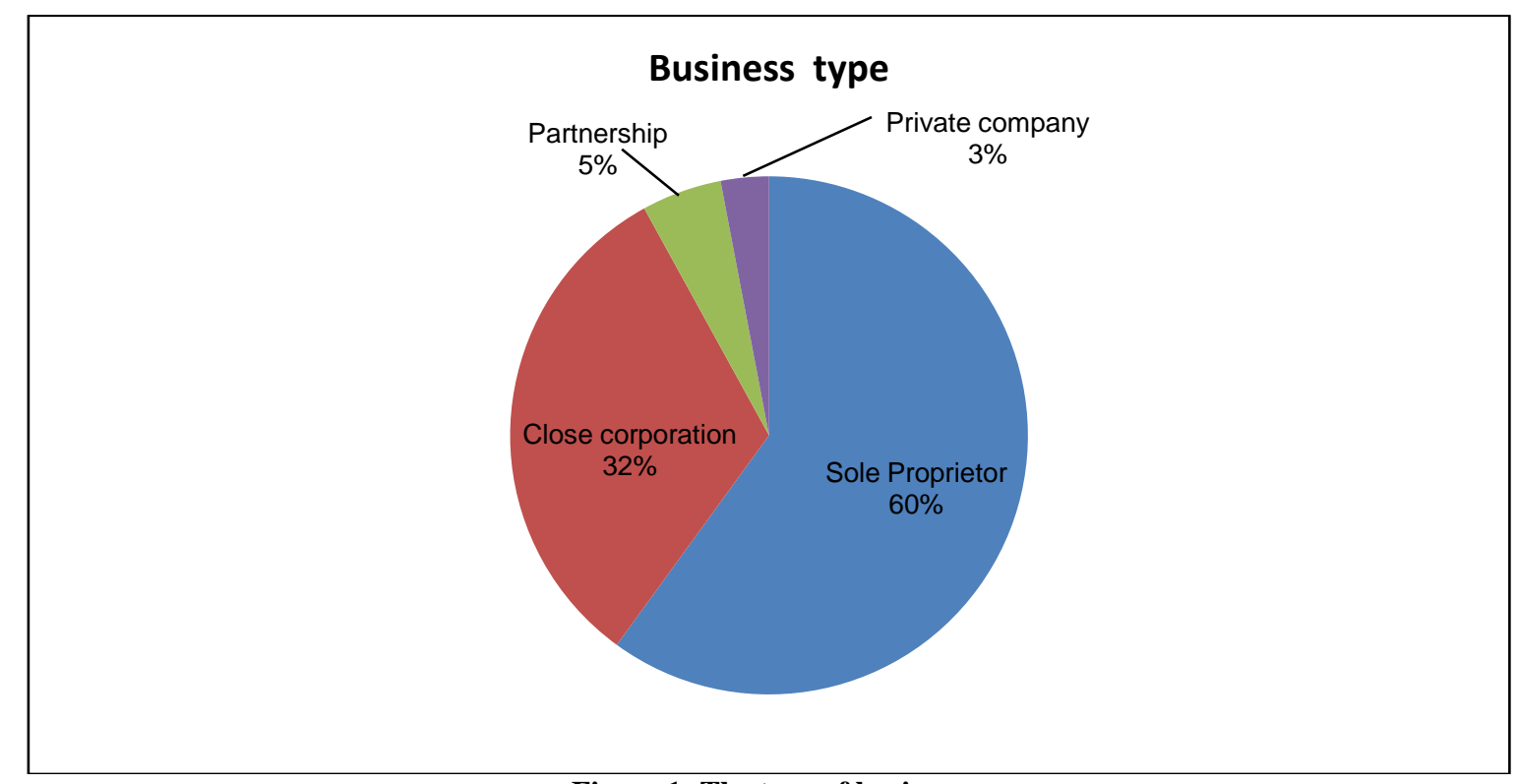

Figure 1: The type of business 


\section{Survey Population Characteristics}

Respondents were asked to indicate their business type, socio-economic and demographic information for the purpose of the study. Questions such as the respondents' occupational level, gender, age and racial group were asked in the demographics section of the questionnaire. The following information were gathered from the respondents and used to establish the demographic profile of respondents who participated in the study.

As illustrated in Figure 1, the sample consisted of 60 percent sole proprietors, 32 percent close corporations, 5 percent partnerships and 3 percent private companies. Figure 2 below illustrates the position held by respondents who participated in the study. Exactly half $(50 \%)$ of the respondents are both the owner and the manager, while 32 percent are just a manager and 18 percent are just the owner.

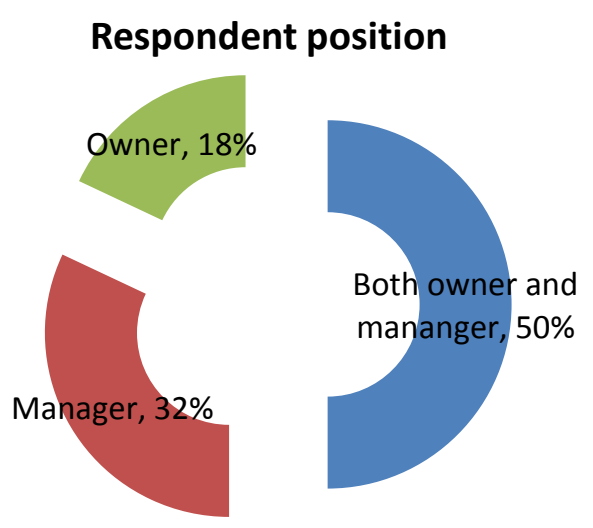

Figure 2: The position held by the respondent

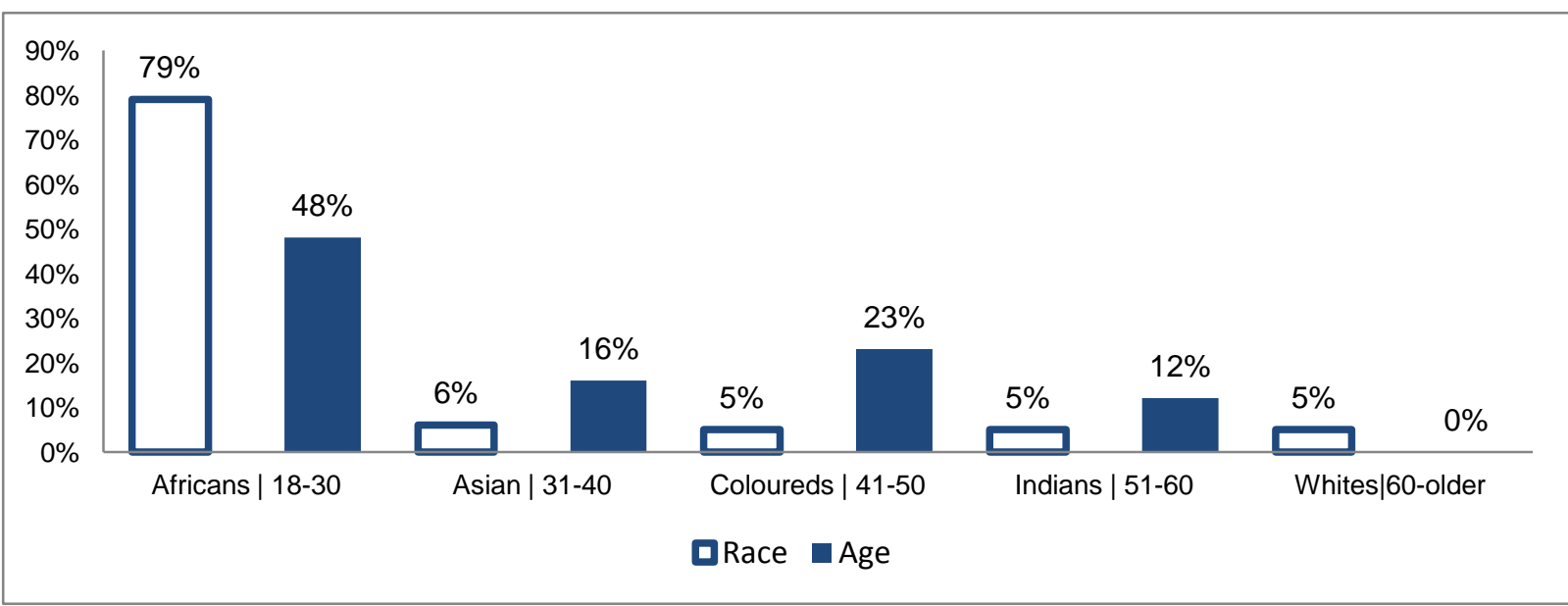

Figure 3: Race and age of respondents

Figure 3 graphically portrays the racial and age profile of respondents who participated in the study. Just fewer than eight in every ten SMEs (79\%) were owned or managed by Africans, 6 percent by Asians and 5 percent by Coloureds, Indians and Whites respectively. On the other hand, about half (48\%) of respondents are between the ages of 18-30, 16 percent between the ages of 31-40, 23 percent between the ages of 41-50 and 12 percent between the ages of 51-60. 


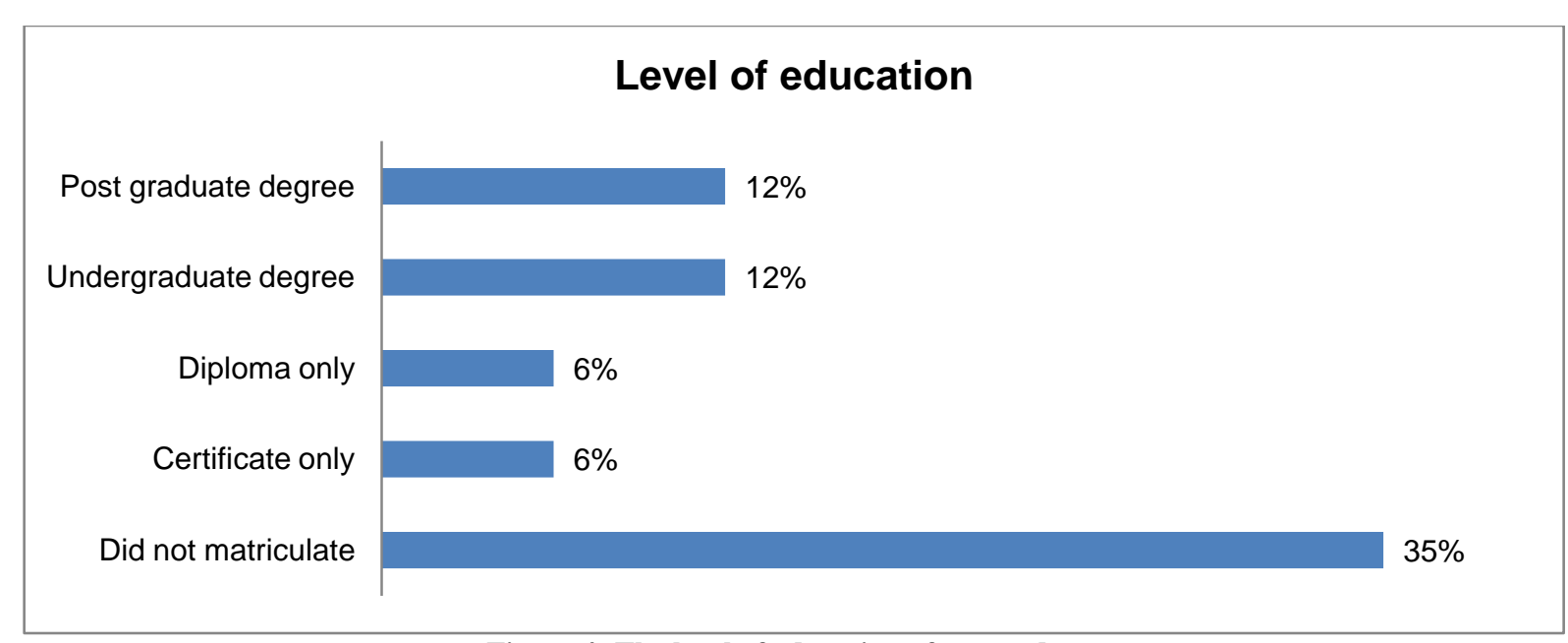

Figure 4: The level of education of respondents

Figure 4 illustrates the level of education of the respondents. About a third (35\%) of respondents did not graduate matric, while the rest have matric (6\%), an undergraduate degree (12\%) and a post-graduate degree (12\%). Roughly two thirds of the respondents are male (58\%) and the rest are female (42\%).

\section{Macro Environment}

This question in the survey was in the form of a 5-item Likert scale. Respondents were asked to indicated whether they strongly disagreed (1) or strongly agreed (5) with the statement. The mean is calculated by adding a list of scores and dividing them by the total number of scores (Wellman, Kruger \& Mitchell, 2007). Standard deviation is the most commonly used and most important measure of variability in statistics which uses the mean as reference point and measures variability by calculating the distance between each score and the mean (Gravetter \& Wellnaue, 2009). Table 1 depicts the mean scores and standard deviation of the impact that macro environmental variables have on SMEs.

Table 1: Macro environmental variables*

\begin{tabular}{|l|c|c|c|c|c|c|c|c|c|}
\hline & $\mathbf{4 . 1}$ & $\mathbf{4 . 2}$ & $\mathbf{4 . 3}$ & $\mathbf{4 . 4}$ & $\mathbf{4 . 5}$ & $\mathbf{4 . 6}$ & $\mathbf{4 . 7}$ & $\mathbf{4 . 8}$ & Total \\
\hline Mean & 3.789 & 2.947 & 3.868 & 3.921 & 4.658 & 2.684 & 2.947 & 4.053 & $\mathbf{3 . 6 5 0}$ \\
\hline St. Deviation & 1.018 & 1.089 & 0.414 & 1.1 & 0.745 & 0.873 & 1.138 & 0.692 & $\mathbf{0 . 9 2 2}$ \\
\hline
\end{tabular}

* Measurement was done on a 5-point Likert scale, whereby $1=$ Strongly disagree and $5=$ Strongly agree.

From Table 1 it can be seen that the highest degree of agreement was for statement 5 , "crime" (Mean = 4.658). This is followed by statement 8 , "government legislation" (Mean $=4.053$ ) and then statement 4 , "unemployment" (Mean = 3.921). The lowest degree of agreement was found to have come from statement 6 , "HIV/Aids" (Mean = 2.684). The standard deviation for statement 7, "technological advances" is high, indicating a large distribution of value in the question.

From the statements that were asked, it is clear that the macro environmental variables listed do affect SMEs, with a total mean score of 3.650 and standard deviation of 0.922 . Figure 5 is thus indicative as to these statements and graphically presents the degree of agreeability and disagreeability. 


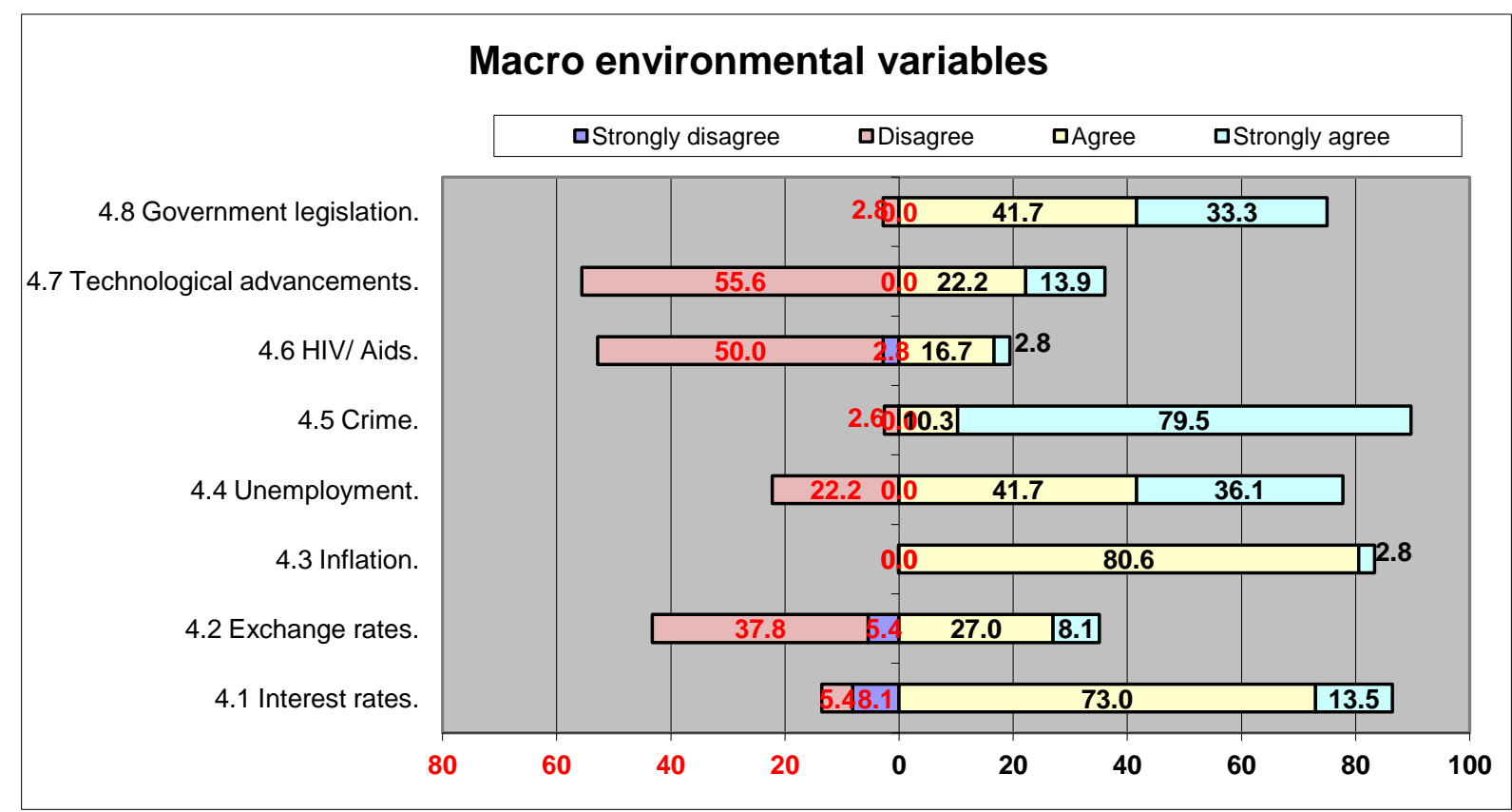

Figure 5: Macro environmental variables affecting SMEs

The majority of respondents agreed that crime impacted SMEs (93.2\%) and government legislation plays an important role $(81.1 \%)$. It is also evident from Figure 5 that respondents agree that, unemployment $(78.4 \%)$, inflation (77.4\%) and interest rates (75.8\%) also influences SMEs. Only about half of the respondents (53.7\%) stated that HIV/Aids affected their business.

It is evident that crime is a major issue not only affecting SMEs but South Africa as a whole. SMEs likely have direct losses due to theft and indirect losses due to security costs, both reducing profits and averting funds that could have been invested into the business. In addition, the majority of SMEs require funding from financial institutions and therefore interest rates is a key distress. On the other hand, inflation not only affects SMEs but also their consumers as it increases the costs of goods and decreases their disposable income. Inflation results in the increase of expenses which again reduces the profits of SMEs and diverts investment to ensure the growth and success of the business. The various variables mentioned above may result in the matter of unemployment, as crime, interest rates and inflation are burdens on SME funds therefore businesses simply do not have the necessary means to hire staff. Lastly, even though the South African government has various initiatives to support SMEs the various legislations in place make it difficult to start up, run and grow SMEs within the country.

\section{Marketing Related Issues}

In this 5-point Likert-scale question, respondents were asked to rate nine statements. These statements attempted to determine the various marketing related problems that SMEs experienced. Respondents had to indicate whether they strongly disagree (1) or agree (5) with each of these statements. Table 2 depicts the mean scores and standard deviation of the perception of SMEs and the marketing problems they experience.

Table 2: Marketing related issues*

\begin{tabular}{|c|c|c|c|c|c|c|c|c|c|c|c|}
\hline & 5.1 & 2.2 & 5.3 & 5.4 & 5.5 & 5.6 & 5.7 & 5.8 & 5.9 & 5.10 & Total \\
\hline Mean & 3.816 & 4.158 & 3.289 & 4.184 & 3.316 & 2.895 & 4.079 & 4.105 & 2.868 & 3.868 & 3.658 \\
\hline St. Deviation & 0.692 & 0.594 & 0.835 & 0.73 & 1.016 & 1.06 & 0.749 & 0.863 & 1.277 & 0.704 & 0.852 \\
\hline
\end{tabular}

$*$ Measurement was done on a 5-point Likert scale, whereby $1=$ Strongly disagree and $5=$ Strongly agree.

From Table 2 it can be seen that the highest degree of agreement was for statement 5 , "wrong pricing strategies" (Mean $=4.184)$. This is followed by statement 2, "low demand for products" $($ Mean $=4.333)$ and 
statement 8 "the location of my business". The lowest degree of agreement was found to have come from statement 9 , "the variety of product offerings" (Mean $=2.868)$.

From all the statements that were asked, the lack of marketing knowledge negatively affects the success of SMEs, with a total mean score of 3.658 and a total standard deviation of 0.852 . Figure 6 illustrates this statement and presents the degree of disagreeability and agreeability.

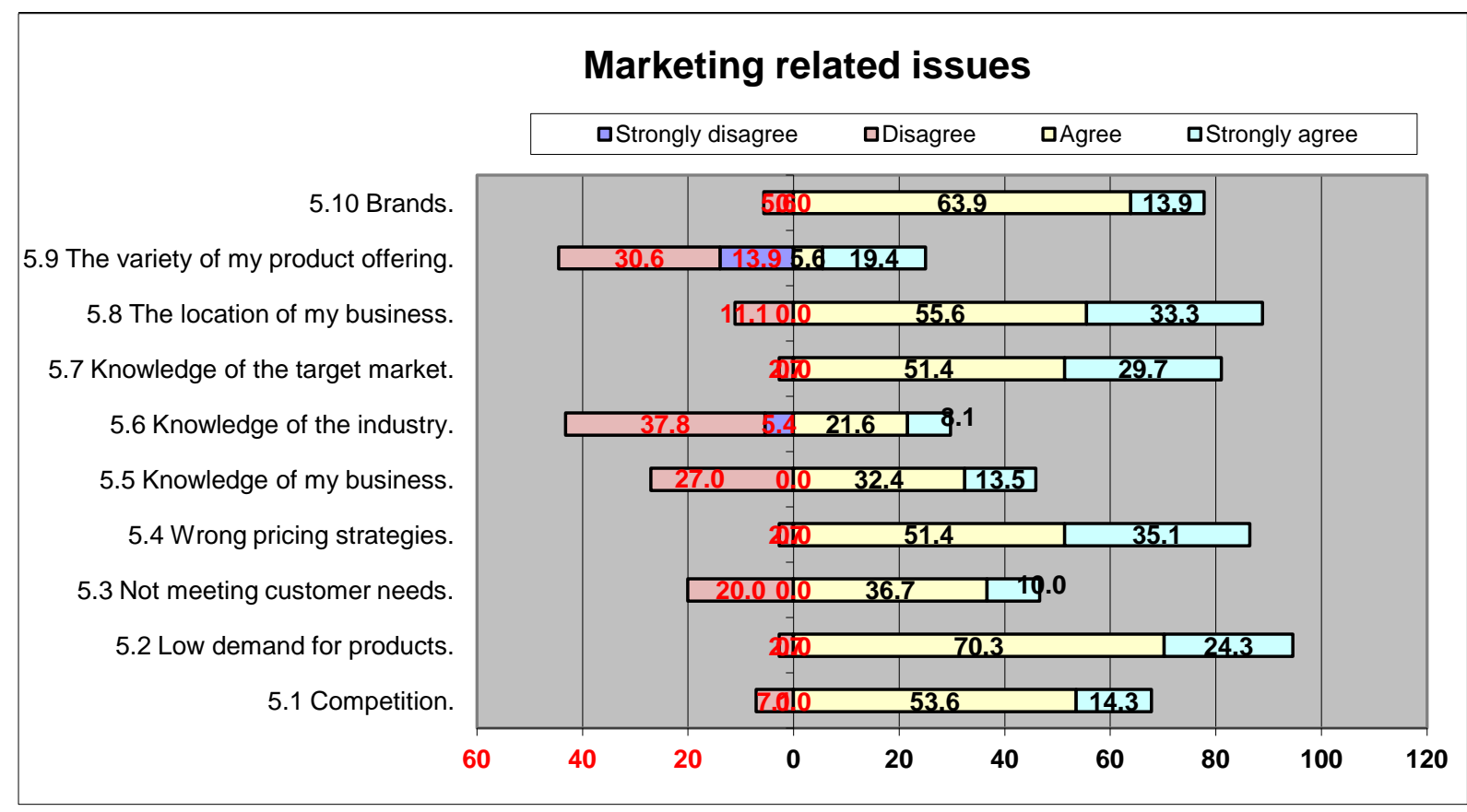

Figure 6: Marketing related issues

Figure 6 illustrates the various marketing related issues that SMEs encounter. The majority of respondents agreed that the wrong pricing strategies being implemented $(83.7 \%)$ and a low demand for their products $(83.2 \%)$ are major concerns followed by "the location of my business" $(82.1 \%)$ and knowledge of my target market $(82.1 \%)$. It is also evident from Figure 6 that respondents agree that competition (76.3\%) and "brands" (77.4\%) also influence SMEs. Only about half of the respondents stated "knowledge of the industry (57.9\%) and "the variety of my product offering" (57.4\%) affected their business.

The issues of the wrong pricing strategies and low demand for products could go hand in hand as the prices could either be too low resulting in consumers thinking the quality of the product may not be up to standard or too high resulting in consumers seeking competitors' products. Alternatively, the low demand for products could be that the SMEs do not have sufficient knowledge of their target audience in order to market and adjust their strategies accordingly. Conversely the location of the business could simply be the reason as to why there are low demands for products as it is inconvenient for the consumers to purchase from the business.

A brand is an important concept in marketing. SMEs, due to its nature, may struggle to build a reputable brand name that consumers acknowledge and trust. As a result, competitors with established well known brands are an issue that SMEs need to overcome. On the other hand, even competition with other SMEs need to be addressed as they may have trouble building their brand which differentiates them from competitors.

As mentioned above, the various macro environmental variables reduce profits and avert funds that could have been invested into the business elsewhere causing many SMEs to not have sufficient resources available to invest in their marketing strategies. 


\section{LIMITATIONS}

The limitations of this study need to be acknowledged and taken into consideration before any recommendations are made. Firstly the sampling size that was used was very small $(n=81)$, therefore variables identified cannot be generalised to be representative of all South African SMEs. Secondly, since the sample size is so small, it is evident that not all SMEs were approached therefore the results cannot be representative of all SMEs in the Tshwane region.

\section{RECOMMENDATIONS}

It has been emphasised that SMEs play a crucial role in the economy, but many struggle to operate in the complex and competitive business environment. Even though macro environmental and marketing variables are universal, some are country or region specific. For instance, the study shows that crime is the leading macro environmental variable affecting South African SMEs.

- $\quad$ Training programmes and workshops targeting SMEs should incorporate the key variables identified in order to be focused and specific on the problems experienced by South African SMEs and allow for practical application of concepts and procedures.

- Associations and representative bodies should be formed which focuses on the key variables such as crime prevention tips and methods.

- $\quad$ Negotiations should be done with local government to increase its role in supporting SMEs according to the specific key variables identified

- The marketing of SMEs should include aspects of the "Proudly South African" initiative and also the endorsement of supporting local SMEs.

\section{CONCLUSIONS}

SMEs in South Africa play an essential role in the development of South Africa's economy and have become the primary source of job creations. These SMEs are faced with a variety of exogenous and endogenous variables which are not only affecting its day to day business but its long term success and survival. The aim of this study was to determine the key variables specifically affecting South African SMEs. The research formulated two objectives to establish the key macro environmental and marketing variables affecting South African SMEs. The results reflected in the study indicate that crime, government legislation, unemployment and inflation and interest rates are the key macro environmental variables affecting South African SMEs. On the other hand, the wrong pricing strategies, low demand for products, location of the business and the knowledge of the target audience are the main marketing variables. Future research can be done on other regions and sectors in South Africa and comparisons can be done.

\section{AUTHOR INFORMATION}

Prof. Michael C. Cant is the CoD of the Department of Marketing and Retail Management at the University of South Africa (UNISA). He has published over 30 accredited articles in refereed journals and is the editor and author of more than 30 books in marketing. These books are widely prescribed at universities in South Africa. He has presented papers at more than 45 international conferences all over the world and is a well respected marketing and retail scholar. He holds a DCom in Marketing from the University of South Africa. Prof. Michael C. Cant, DCom, University of South Africa (UNISA), Department of Marketing and Retail Management, P. O Box 329, UNISA, 0003, South Africa. E-mail: cantmc@unisa.ac.za (Corresponding author)

Prof. Johannes A. Wiid is an Associate Professor in the Department of Marketing and Retail Management at the University of South Africa. He has published extensively in various refereed journals and is the editor and author of more than 5 books in marketing. These books are widely prescribed at universities in South Africa. He holds a DCom in Marketing from the University of Johannesburg. E-mail: jwiid@unisa.ac.za 


\section{REFERENCES}

1. Brink, A., Cant, M.C. \& Ligthelm, A. (2003). Problems experienced by small businesses in South Africa. Retrieved from: http://www.cecc.com.au/programs/resource_manager/accounts/seaanz_papers/NewdocCant.pdf

2. Cant, M.C. \& Lightelm, A. (2003). Small business problems in the South African context: a proactive entrepreneurial approach. Retrieved from: http://www.itdweb.org/smeconference/documents/plenary/PI\%20Berry\%20ENG.pdf

3. Fatoki, O. and Garwe, D. (2010). Obstacles to the growth of new SMEs in South Africa: a principal component analysis approach. [Online] available from: http://www.academicjournals.org/AJBM/PDF/pdf2010/May/Olawale\%20and\%20Garwe.pdf

4. Fatoki, O. \& Odeyemi, A. (2010). The determinants of access to trade credit by new SMEs in South Africa. Retrieved from:

http://www.academicjournals.org/ajbm/PDF/pdf2010/4Oct/Olawale\%20and\%20\%20Akinwumi.pdf

5. Government Gazette of the Republic of South Africa. (2003). National small business amendment act.

6. Kongolo, M. (2010). Job creation versus job shedding and the roles of SMEs in economic development. Retrieved from: http://www.academicjournals.org/Ajbm/PDF/pdf2010/4Sept/Kongolo.pdf

7. Robert, J. (2010). Small business failure rates as high as $63 \%$ in first two years. Retrieved from: http://www.businesslive.co.za/southafrica/sa_companies/2010/11/16/small-business-failure-rate-63-in-firsttwo-years

8. Sha, S. (2006). An investigation into problems facing small-to-medium sized enterprises in achieving growth in the Eastern Cape: enhancing the strategy for developing small 'growth potential' firms in the Eastern Cape. Retrieved from: http://eprints.ru.ac.za/288/1/Sha-TR06-146.pdf

9. Van Scheers, L. (2012). Marketing related challenges of small and medium enterprises (SMEs) in developing African countries: the South African challenge. 
NOTES 